\title{
Increased Vulnerability of the Aging Stomach to NSAIDs
}

\author{
Mario Guslandi
}

Received: 5 February 2013/Accepted: 18 February 2013/Published online: 16 March 2013

(C) Springer Science+Business Media New York 2013

To the Editor,

The interesting experimental findings reported by Hong et al. in rats provide new insights on the mechanisms underlying NSAID-induced gastric damage in the aging stomach, emphasizing the possible role of both redox activation and up-regulation of pro-inflammatory mediators [1].

Challenging our current belief that a deficiency in gastric prostaglandin levels is the main cause of NSAID gastropathy, they also report no difference between PGE2 levels in young and old rat stomach, with an increase in the PGE2 secretion in old rats after indomethacin administration.

In their editorial, Tang and Chan [2] have already wisely commented upon these paradoxical findings by pointing out that the indomethacin-induced increase in PGE2 levels may be a transient phenomenon, possibly related to upregulation of COX-2 expression, and suggesting that, after all, the age-related decline in mucosal defences may not be entirely PGE2-dependent.

Years ago we assessed the behaviour of gastric mucus and bicarbonate secretion, as well as local microcirculation (as measured by laser Doppler flowmetry) in healthy subjects of different age [3]. We found that in elderly patients both mucus and bicarbonate secretion are significantly reduced and gastric microcirculation is significantly impaired. Thus, in aged humans, gastric mucosal defences are indeed defective. It remains to be determined whether this is due to a decreased production of gastric prostaglandins, as we suggested at that time, or to a gradual replacement of the aging gastric mucosa by connective tissue, as recently postulated [4].

Whatever the truth, further studies are needed in order to identify the best therapeutic strategies to effectively protect the aging gastric mucosa from the damaging effect of NSAIDs beyond the mere gastric acid reduction by proton pump inhibitors.

\section{References}

1. Hong K, Kim EH, Lee HJ, Kim YJ, Lee JJ, Hahm KB. Molecular mechanisms elucidating why old stomach is more vulnerable to indomethacin-induced damage than young stomach. Dig Dis Sci. 2013;58:61-71.

2. Tang RS, Chan FKL. Mechanisms behind the increased vulnerability of the aging stomach to NSAID-related injury: perhaps not as simple as we may think. Dig Dis Sci. 2013;58:11-12.

3. Guslandi M, Pellegrini A, Sorghi M. Gastric mucosal defences in the elderly. Gerontology. 1999;45:206-208.

4. Kang JM, Kim N, Kim JH, et al. Effect of aging on gastric mucosal defense mechanisms: rOS, apoptosis, angiogenesis and sensory neurons. Am J Physiol Gastrointest Liver Physiol. 2010;299: G1147-G1153. 